\title{
A microRNA-17-5p/homeobox B13 axis participates in the phenotypic modulation of vascular smooth muscle cells
}

\author{
TIANCHI YU ${ }^{1 *}$, TAO WANG $^{1 *}$, SHIFANG KUANG ${ }^{2}$, GUOPING ZHAO $^{3}$, \\ $\mathrm{KUN}_{\mathrm{ZHOU}}{ }^{3}$ and HUI ZHANG ${ }^{1}$ \\ ${ }^{1}$ Department of Vascular Surgery; ${ }^{2}$ Center of Endoscopy; ${ }^{3}$ Department of General Surgery, \\ Jiangning Hospital Affiliated to Nanjing Medical University, Nanjing, Jiangsu 211100, P.R. China
}

Received April 13, 2021; Accepted July 26, 2021

DOI: $10.3892 / \mathrm{mmr} .2021 .12370$

\begin{abstract}
Vascular smooth muscle cells (VSMCs) serve a decisive role in intimal hyperplasia, a common pathophysiological process that leads to numerous vascular disorders. The present study aimed to investigate the unknown mechanisms underlying VSMC phenotypic modulation and identified a novel microRNA (miRNA/miR)-17-5p/homeobox B13 (HOXB13) axis involved in the phenotypic switching, proliferation and migration of VSMCs. VSMCs were isolated from the thoracic aorta of Sprague-Dawley rats, cell proliferation was determined by Cell Counting Kit-8 (CCK-8) assay, cell migration was examined by Transwell migration assay and gene expression was detected using reverse transcription-quantitative PCR and western blot analyses. It was firstly found that incubation with platelet-derived growth factor-BB (PDGF-BB) recombinant protein resulted in a significant increase in $\mathrm{HOXB} 13$ expression in VSMCs. Using multiple miRNA prediction tools, miR-17-5p was identified as a potential regulator for HOXB13, since it had a 7-base perfect binding site and a 5-base imperfect binding site with the 3'-untranslated region of HOXB13 mRNA, and these sequences were highly conserved across species. The regulatory effect of miR-17-5p on HOXB13 was validated using luciferase reporter assays. The expression level of miR-17-5p was increased in VSMCs under PDGF-BB stimulation, and was negatively correlated with HOXB13 mRNA and protein expression. Moreover, the miR-17-5p mimics significantly inhibited the proliferation and migration of VSMCs, while antagomiR-17-5p showed the opposite effects, which could be abolished by HOXB13 knockdown. The miR-17-5p/HOXB13 axis also regulated the expression levels of the markers of
\end{abstract}

Correspondence to: Dr Hui Zhang, Department of Vascular Surgery, Jiangning Hospital Affiliated to Nanjing Medical University, 169 Hushan Road, Nanjing, Jiangsu 211100, P.R. China E-mail: zhaunig120@sina.com

*Contributed equally

Key words: vascular smooth muscle cells, microRNA-17-5p, homeobox B13, phenotypic switching, proliferation, migration differentiated VSMCs ( $\alpha$-smooth muscle actin, transgelin and smoothelin), proliferating cell nuclear antigen and cell migration proteins, including MMP-2 and -9. In conclusion, the present study demonstrated that miR-17-5p inhibited the phenotypic modulation VSMCs stimulated by PDGF-BB by downregulating HOXB13, indicating that these factors may be potential therapeutic targets for intimal hyperplasia.

\section{Introduction}

Vascular smooth muscle cells (VSMCs) are the main cellular components of blood vessels and serve a key role in intimal hyperplasia, a pathophysiological process that causes numerous vascular disorders, such as atherosclerosis, hypertension and post-angioplasty restenosis (1). VSMCs are not terminally differentiated and maintain considerable diversity and plasticity. For instance, these cells undergo phenotypic switching under the action of locally produced growth factors, such as platelet-derived growth factor-BB (PDGF-BB), and migrate to the intima and proliferate to induce intimal disease (1). During the process of neointima formation, VSMCs are characterized by decreased expression levels of genes associated with cell differentiation and contraction, as well as increased proliferation, migration and synthesis of extracellular matrix components, which lead to the conversion to a synthetic phenotype (2). Therefore, investigating the mechanisms underlying VSMC phenotypic modulation is essential for developing effective treatments in the management of vascular intimal hyperplasia.

MicroRNAs (miRNAs/miRs) are a cluster of non-coding RNAs containing 19-25 nucleotides that can regulate $>60 \%$ of human genes involved in almost all the cellular biological behaviors, including proliferation, migration and differentiation (3). miRNAs exert their biological functions mainly by binding to the 3'-untranslated region (3'-UTR) of target genes, leading to the degradation or/and preventing the translation of mRNA, thereby negatively regulating gene expression in a post-transcriptional manner (4). Accumulating evidence has shown the significance of miRNAs in vascular diseases and their potentials as therapeutic targets (5). For example, some miRNAs, such as miR-21, miR-26a and miR-29b, have been reported to participate in arterial intimal hyperplasia by regulating the phenotypic switching of VSMCs (6). 
Homeobox B13 (HOXB13) belongs to the homeobox family and is a master regulator in cell identity, differentiation, proliferation and migration during embryonic development, tumorigenesis and inflammatory reactions $(7,8)$. In particular, homeobox genes are involved in vasculogenesis and vascular remodeling, which are common events during neointimal lesion formation in atherosclerosis and post-angioplasty restenosis (9). Moreover, HOXB13 is a well-known regulator of the terminal differentiation of prostate epithelial cells and represents an important biomarker for prostate cancer (10). However, it remains unknown whether HOXB13 participates in regulating the phenotypic switching, proliferation and migration of VSMCs, and the upstream regulatory miRNAs in VSMCs are yet to be determined. Therefore, present study aimed to investigate the mechanisms underlying VSMC phenotypic modulation.

\section{Materials and methods}

Regents and antibodies (Abs). Recombinant PDGF-BB protein was purchased from Sigma-Aldrich (Merck KGaA). Abs against HOXB13 (cat. no. sc-28333), proliferating cell nuclear antigen (PCNA; cat. no. sc-56), $\alpha$-smooth muscle actin ( $\alpha$-SMA; cat. no. sc-53142), transgelin (cat. no. sc-53932), smoothelin (cat. no. sc-376902), MMP-2 (cat. no. sc-13594), MMP-9 (cat. no. sc-21733) and $\beta$-actin (cat. no. sc-47778) were purchased from Santa Cruz Biotechnology, Inc.

Isolation and culture of VSMCs. In total, six male specific pathogen-free Sprague-Dawley rats (age, 8 weeks; body weight, $250 \pm 20 \mathrm{~g}$ ) were obtained from the Animal Laboratory of Nanjing Jiangning Hospital (Nanjing, China). Rats were housed at $23 \pm 2^{\circ} \mathrm{C}$ under a controlled humidity (45-65\%) with free access to food and water under a 12-h light/dark cycle. Rats were intraperitoneally injected with $3 \%$ sodium pentobarbital $(100 \mathrm{mg} / \mathrm{kg})$. Immediately after the loss of consciousness, rats underwent thoracotomy and the thoracic aorta was quickly dissected and separated. At this stage, the rats were dead. After being rinsed with PBS, a section of the artery was soaked in sterile Hanks balanced salt solution. The outer membrane was gently peeled, and the artery was cut into small pieces of $0.5-1 \mathrm{~mm}^{3}$ and placed in a $25-\mathrm{ml}$ culture flask with a distance of $\sim 0.5 \mathrm{~cm}$. The flask was placed in a $37^{\circ} \mathrm{C}$ incubator with a humidified atmosphere of $5 \% \mathrm{CO}_{2}$, and $3 \mathrm{~h}$ later DMEM (Gibco; Thermo Fisher Scientific, Inc.) supplemented with 10\% FBS (Thermo Fisher Scientific, Inc.), $100 \mathrm{U} / \mathrm{ml}$ penicillin and $100 \mu \mathrm{g} / \mathrm{ml}$ streptomycin was added. The media were refreshed every 3-5 days. When cells grew to $\sim 70 \%$ confluence, they were sub-cultured with trypsinization. Moreover, 5-6 generations of cells were used for the experiments.

Cell proliferation assay. VSMCs were seeded at a density of $3 \times 10^{3}$ cells/well in 96-well plates and incubated overnight with DMEM supplemented with 10\% FBS. The medium was removed and the plates were washed with PBS. The same volume of serum-free medium was added and cells were cultured for $12 \mathrm{~h}$. After being washed with PBS, cells were incubated at $37^{\circ} \mathrm{C}$ for $24 \mathrm{~h}$ with recombinant $\mathrm{PDGF}-\mathrm{BB}$ protein at $1,2,4,8,16$ or 32 or $15 \mathrm{ng} / \mathrm{ml}$ PDGF-BB protein at $37^{\circ} \mathrm{C}$ for $6,12,18,24,30$ or $36 \mathrm{~h}$.
A Cell Counting Kit-8 (CCK-8) assay (Dojindo Molecular Technologies, Inc.) was used to determine cell proliferation according to the manufacturer's instructions. The culture medium was replaced with $100 \mu \mathrm{l}$ fresh serum-free medium containing $10 \mu \mathrm{l}$ CCK-8 solution. The cells were further incubated for $2 \mathrm{~h}$ at $37^{\circ} \mathrm{C}$, and the optical density (OD) at $450 \mathrm{~nm}$ was measured. The cell proliferation rate (\%) was calculated using the following formula: (Experimental OD-control OD)/ control OD x $100 \%$.

Migration assay. Transwell chambers $(8-\mu \mathrm{m}$ pore size) were purchased from BD Bioscience. Cells $\left(2 \times 10^{4}\right)$ suspended in $200 \mu \mathrm{l}$ serum-free medium were seeded on the polycarbonate membrane in the upper Transwell chamber, which was incubated for $60 \mathrm{~min}$ at $37^{\circ} \mathrm{C}$ with $5 \% \mathrm{CO}_{2}$. The lower chamber was then filled with $750 \mu \mathrm{l}$ medium with $5 \%$ FBS. After being incubated for 12,24 or $36 \mathrm{~h}$ at $37^{\circ} \mathrm{C}$ in a humidified atmosphere of $5 \% \mathrm{CO}_{2}$, the Transwell chamber was washed with PBS and cells on the top surface of the polycarbonate membrane were removed. At room temperature, cells that migrated to the bottom surface of the insert were fixed with $100 \%$ methanol for $20 \mathrm{~min}$ and stained with $0.25 \%$ crystal violet solution for 10 min. Using light microscopy, the cells were counted from digital images, with 10 visual fields captured randomly at a magnification of $\mathrm{x} 200$.

Prediction of potential miRNAs. Multiple miRNA prediction tools [miRWalk (version 2.0; http://mirwalk.umm.uni-heidelberg.de/), TargetScan (version 7.1; targetscan.org/), miRanda (version 1.9; omictools.com/miranda-tool), miRTarBase (version 2.0; mirtarbase.mbc.nctu.edu.tw/) and mirdb (mirdb. org/)] were used to predict the potential upstream miRNAs that can regulate HOXB13 gene by targeting its 3'-UTR.

Reverse transcription-quantitative PCR (RT-qPCR). Total RNA was extracted from cell lysates using TRIzol ${ }^{\circledR}$ reagent (cat. no. 15596026; Thermo Fisher Scientific, Inc.) according to the manufacturer's instructions. RNA quantity and quality were measured using a NanoDrop ND-1000 system. For amplifying miR-17-5p, RNA was reversely transcribed into cDNA using a TaqMan ${ }^{\circledR}$ MicroRNA Reverse Transcription kit (cat no. 4366597; Thermo Fisher Scientific, Inc.) according to the manufacturer's protocol, and a stem-loop RT primer (5'-GTCGTATCCAGTGCAGGTATTCGCACTGGA TACGACCTACC-3'), a sense primer (5'-TGCAAAGTGCTT ACAGTGCAG-3') and an antisense primer (5'-GTGCAGGGT CCGAGGTATTC-3') were used. U6 RNA expression served as a positive control, using a pair of primers: Sense, 5'-CTC GCTTCGGCAGCACA-3' and antisense, 5'-AACGCTTCA CGAATTTGCGT-3'. For amplifying HOXB13 mRNA, RNA was reversely transcribed into cDNA using TaqMan ${ }^{\mathrm{TM}}$ Reverse Transcription Reagents (cat. no. N8080234; Thermo Fisher Scientific, Inc.) according to the manufacturer's protocol, and a pair of primers (sense, 5'-CAGATGTGTTGCCAGGGAGA-3' and antisense, 5'-AGGCGTCAGGAGGGTGCT-3') were used. The expression level of GAPDH served as an internal control, using a pair of primers: Sense, 5'-GAAATCCCATCACCA TCTTCCAGG-3' and antisense: 5'-GAGCCCCAGCCTTCT CCATG-3'. Following RT, qPCR was performed using an Applied Biosystems 7500 Real-Time PCR system and SYBR 
Green (cat. no. S7563; Thermo Fisher Scientific, Inc.) according to the manufacturer's instruction. The thermocycling conditions were as follows: $10 \mathrm{~min}$ initial denaturation at $94^{\circ} \mathrm{C}$, $15 \mathrm{sec}$ denaturation at $94^{\circ} \mathrm{C}$ and $30 \mathrm{sec}$ of annealing at $55^{\circ} \mathrm{C}$ (40 cycles) and final extension for $1 \mathrm{~min}$ at $72^{\circ} \mathrm{C}$. Experiments were performed in triplicate, and the relative expression levels were calculated using the $2^{-\Delta \Delta \mathrm{Cq}}$ method (11).

Transfection of oligonucleotides. The miR-17-5p mimics (5'-CAA AGUGCUUACAGUGCAGGUAG-3'), antagomiR-17-5p (5'-CUACCUGCACUGUAAGCACUU UG-3'), mimics negative control (5'-UUCUCCGAACGU GUCACGUTT-3'), antagomiR negative control (5'-UCACAA CCUCCUAGAAAGAGUAGA-3'), small interfering RNA (siRNA) targeting HOXB13 (sense, 5'-GCGGCCGCAAGA AACGCAUTT-3' and antisense, 5'-AUGCGUUUUGUGCGG CCGCTT-3') and siRNA negative control (sense, 5'-UUCUCC GAACGUGUCACGU-3' and antisense, 5'-ACGUGACAC GUUCGGAGAA-3') oligonucleotides were purchased from Shanghai GenePharma Co., Ltd. VSMCs (1x10 $/$ well) were seeded in 6-well plates and cultured with DMEM supplemented with $10 \%$ FBS. When cells were grown to $60-70 \%$ confluence, they were incubated with oligonucleotides at $100 \mathrm{nM}$ using Lipofectamine ${ }^{\circledR}$ RNAiMAX transfection reagent (Thermo Fisher Scientific, Inc.) in serum-free media at $37^{\circ} \mathrm{C}$ for $48 \mathrm{~h}$, and were then immediately subjected to subsequent assays.

Luciferase reporter assay. The 3'-UTR fragment of HOXB13 mRNA containing miR-17-5p-targeting sequence was cloned into a pMIR-REPORT luciferase reporter vector (Ambion; Thermo Fisher Scientific, Inc.) to create wild-type (WT) and mutated type (MT) pMIR-luc-HOXB13-3'-UTR vectors. VSMCs $\left(1 \times 10^{4} /\right.$ well) were cultured in 24 -well plates. When at $60-70 \%$ confluence, cells were co-transfected with the vectors $(100 \mathrm{nM})$, together with $50 \mathrm{nM}$ miR-175p mimics, $50 \mathrm{nM}$ antagomiR-17-5p or $50 \mathrm{nM}$ negative control oligonucleotides using Lipofectamine ${ }^{\circledR} 3000$ (Thermo Fisher Scientific, Inc.) at $37^{\circ} \mathrm{C}$. A luciferase reporter vector without the miR-17-5p targeting sequence was transfected in parallel. After transfection for $48 \mathrm{~h}$, luciferase activities were measured using the Dual-luciferase Reporter Assay system (Promega Corporation) and normalized to Renilla according to the manufacturer's instructions. The relative luciferase activity in cells was expressed as a percentage of the luciferase activity over that of cells transfected with the vector without miR-17-5p targeting sequence.

Western blot analysis. Cells were homogenized in protein lysate buffer (50 mM Tris, $\mathrm{pH} 7.4,100 \mathrm{mM}$ EDTA, 0.25 M sucrose, $1 \% \mathrm{SDS}, 1 \% \mathrm{NP} 40,1 \mathrm{mg} / \mathrm{ml}$ leupeptin, $1 \mathrm{mg} / \mathrm{ml}$ pepstatin A and $100 \mathrm{mM}$ phenyl methyl sulfonyl fluoride), and debris was removed via centrifugation at $10,000 \mathrm{x} g$ for $10 \mathrm{~min}$ at $4^{\circ} \mathrm{C}$. Protein concentrations were determined using the Bio-Rad protein assay (Bio-Rad Laboratories, Inc.). Protein (30 $\mu \mathrm{g} /$ lane) were resolved on $10 \%$ SDS-polyacrylamide gels and then electrophoretically transferred to PVDF membranes, which were blocked in TBS-Tween 20 [137 mM NaCl, $20 \mathrm{mM}$ Tris $\mathrm{HCl}(\mathrm{pH} 7.6)$ and $0.1 \%$ (v/v) Tween 20] containing 5\% (w/v) non-fat dry milk at $37^{\circ} \mathrm{C}$ for $2 \mathrm{~h}$. The membranes were incubated at $4^{\circ} \mathrm{C}$ overnight with primary Abs (Anti-HOXB13,
1:500; anti-PCNA, 1:400; anti- $\alpha$-SMA, 1:1,000; anti-transgelin, 1:1,000; anti-smoothelin, 1:1,000; anti-MMP-2, 1:800; anti-MMP-9, 1:1,000; anti- $\beta$-actin, 1:1,000), followed by an incubation with alkaline phosphatase-conjugated secondary $\operatorname{Abs}(1: 2,000)$ for $2 \mathrm{~h}$ at room temperature in the dark. Membranes were then developed with 5-bromo-4-chloro-3-indolyl phosphate/nitro blue tetrazolium (Tiangen Biotech Co., Ltd.). The density of each band was measured using the ChemiDoc XRS system (Version 3.0; Bio-Rad Laboratories, Inc.) and the semi-quantitative measurement of band density was repeated thrice.

Statistical analysis. GraphPad Prism 8.02 (GraphPad Software, Inc.) was used for statistical analyses. Data are presented as the mean $\pm \mathrm{SD}$. Comparisons were conducted using one-way ANOVA followed by a Tukey's post hoc test. The correlation between HOXB13 and miR-17-5p expression levels was assessed using a Pearson's test. $\mathrm{P}<0.05$ was considered to indicate a statistically significant difference. The experiments were repeated at least three times.

\section{Results}

PDGF-BB stimulates the proliferation and induces phenotypic switching of VSMCs. The stimulation of VSMCs with PDGF-BB protein is widely used as an in vitro functional model for studying vascular intimal hyperplasia (12). VSMCs were first incubated for $24 \mathrm{~h}$ with recombinant PDGF-BB protein at 1,2, 4, 8, 16 or $32 \mathrm{ng} / \mathrm{ml}$, which were selected based on previous studies (12-15). The CCK-8 assay results demonstrated that incubation with the PDGF-BB protein stimulated the proliferation of VSMCs in a concentration-dependent manner (Fig. 1A). Since PDGF-BB exerted its maximal effect at a concentration of $15 \mathrm{ng} / \mathrm{ml}$, this was used for the subsequent experiments. PDGF-BB stimulation also promoted the proliferation of VSMCs in a time-dependent manner when VSMCs were incubated with $15 \mathrm{ng} / \mathrm{ml}$ PDGF-BB protein for $6,12,18,24,30$ or $36 \mathrm{~h}$ (Fig. 1B). The western blot analysis results identified the reduced expression levels of VSMC differentiation-related markers, including $\alpha$-SMA (16), transgelin (also known as smooth muscle 22 $\alpha$ ) (17) and smoothelin (18), and increased expression levels of the proliferation marker PCNA, in VSMCs after PDGF-BB stimulation in a time-dependent manner (Fig. 1C). These results indicated that PDGF-BB can induce the phenotypic switch and stimulate the proliferation of VSMCs.

PDGF-BB promotes the migration of VSMCs. Transwell migration assays revealed that the ability of VSMCs to migrate was significantly enhanced by PDGF-BB protein in a time-dependent manner (Fig. 2A and B). Western blot analysis also confirmed that PDGF-BB stimulation resulted in an upregulation of MMP-2 and MMP-9 expression in a time-dependent manner (Fig. 2C), which are two important mediators of VSMC migration (19).

PDGF-BB stimulation leads to the upregulation of HOXB13 and the downregulation of $m i R-17-5$. It was identified that incubation with $15 \mathrm{ng} / \mathrm{ml}$ PDGF-BB protein increased the mRNA and protein expression levels of HOXB13 in VSMCs 

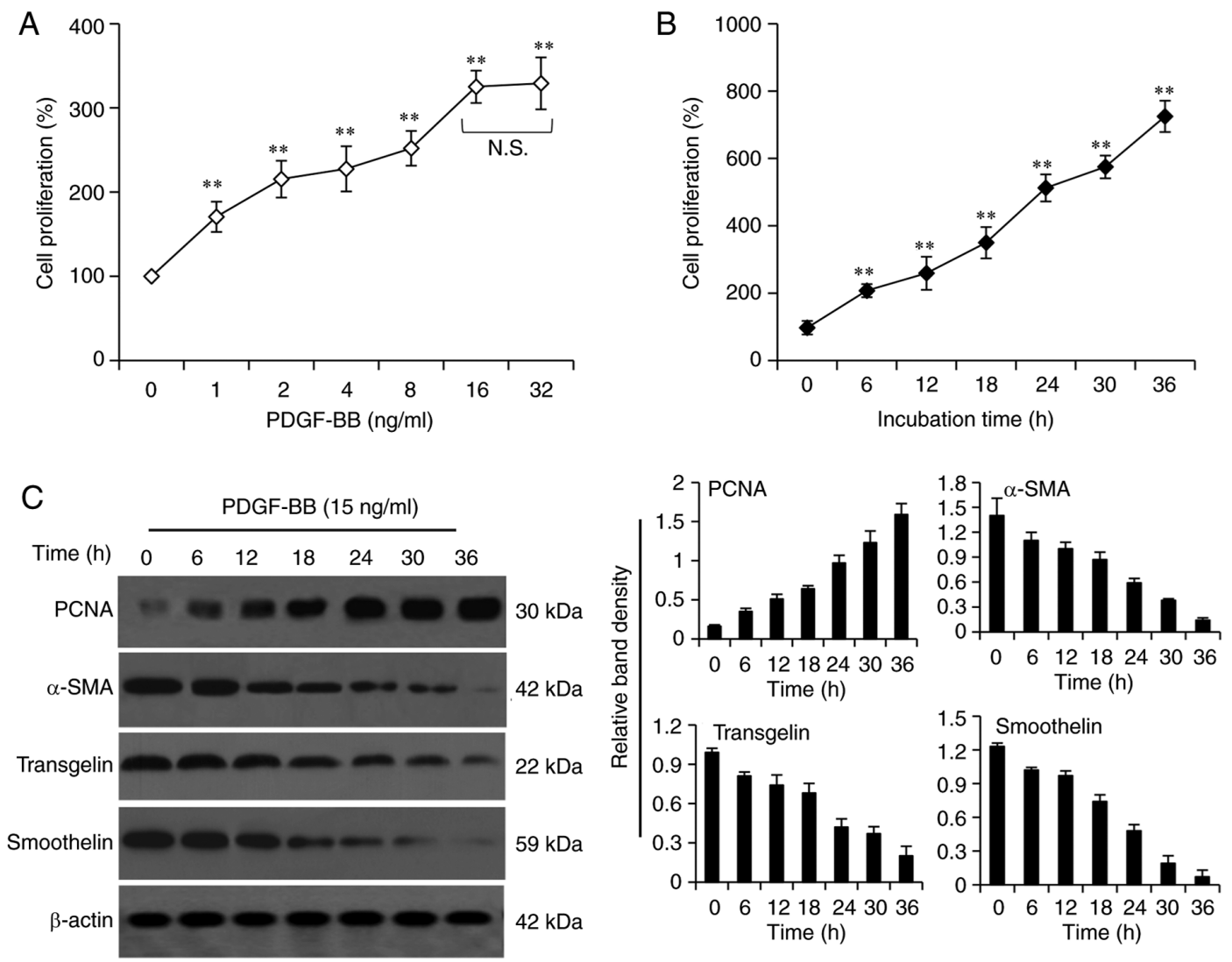

Figure 1. PDGF-BB stimulates the proliferation and induces phenotypic switching of VSMCs. VSMCs were (A) incubated for $24 \mathrm{~h}$ with PDGF-BB protein at different concentrations or (B) incubated with $15 \mathrm{ng} / \mathrm{ml}$ PDGF-BB protein for different periods. Cell proliferation was measured. (C) Cells were subjected to western blot analysis and band density was normalized to $\beta$-actin." $\mathrm{P}<0.001$ vs. untreated VSMCs. N.S., not significant; PDGF-BB, platelet-derived growth factor-BB; VSMCs, vascular smooth muscle cells; PCNA, proliferating cell nuclear antigen; $\alpha$-SMA, $\alpha$-smooth muscle actin.

A

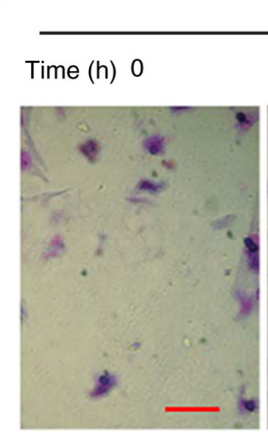

C

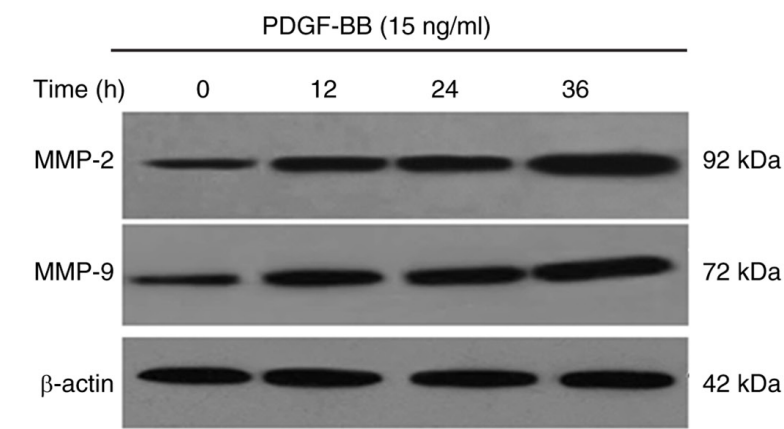

B PDGF-BB (15 ng/ml)

$12 \quad 24$
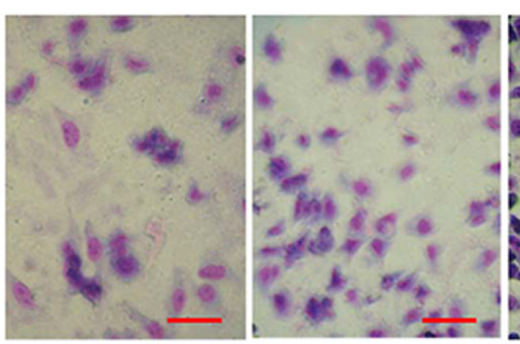

36

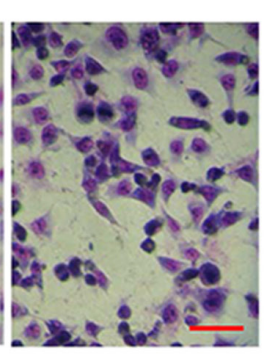

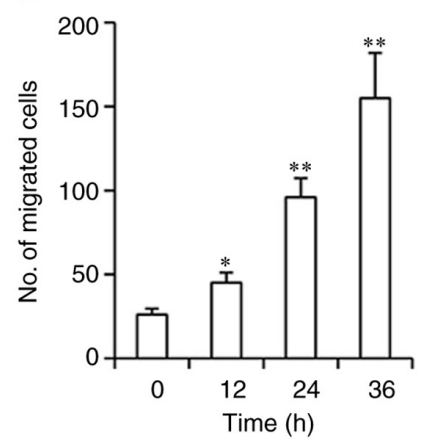

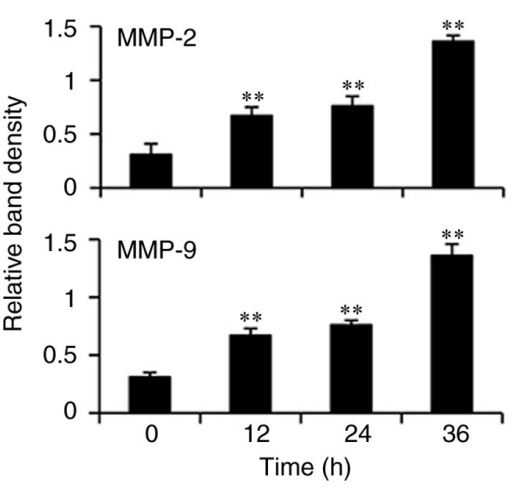

Figure 2. PDGF-BB stimulates the migration of VSMCs. VSMCs were incubated with $15 \mathrm{ng} / \mathrm{ml}$ PDGF-BB protein for different periods in migration assays (A) Migrated cells harvested at 0,12, 24 and $36 \mathrm{~h}$ were stained with crystal violet solution. Scale bar, $100 \mu \mathrm{m}$. (B) The number of migrated cells was counted. (C) Cells were subjected to western blot analysis and band density was normalized to $\beta$-actin. ${ }^{*} \mathrm{P}<0.05$ and ${ }^{* *} \mathrm{P}<0.001$ vs. 0 h. PDGF-BB, platelet-derived growth factor-BB; VSMCs, vascular smooth muscle cells. 
A

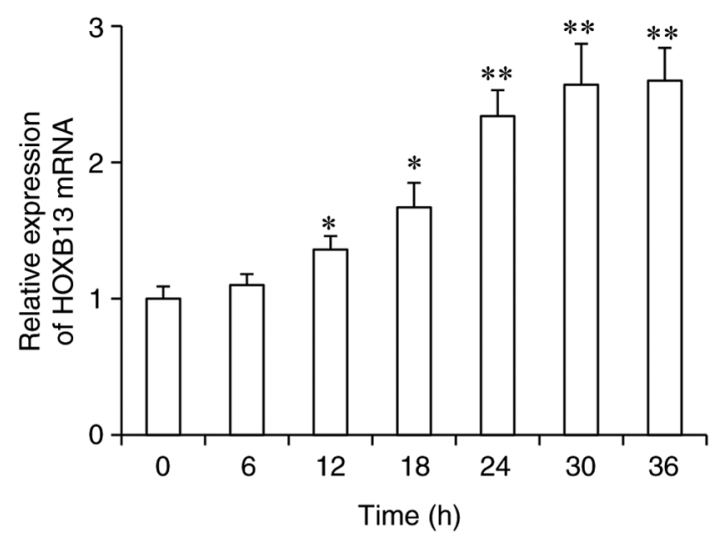

C

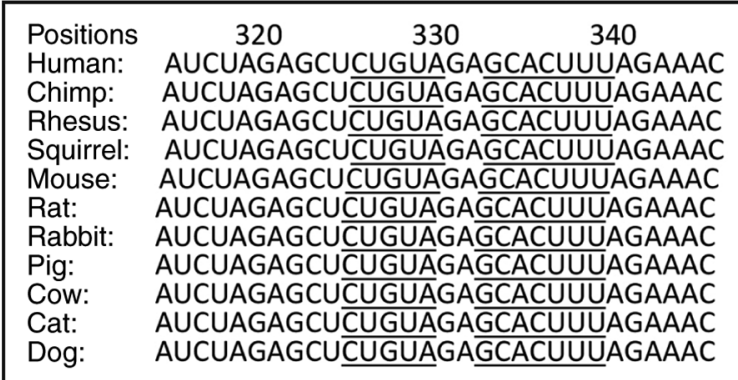

$E$

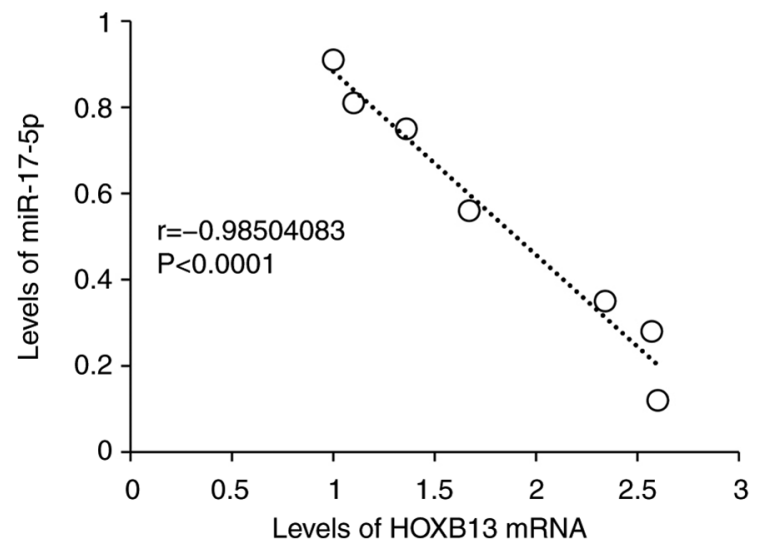

B PDGF-BB (15 ng/ml)
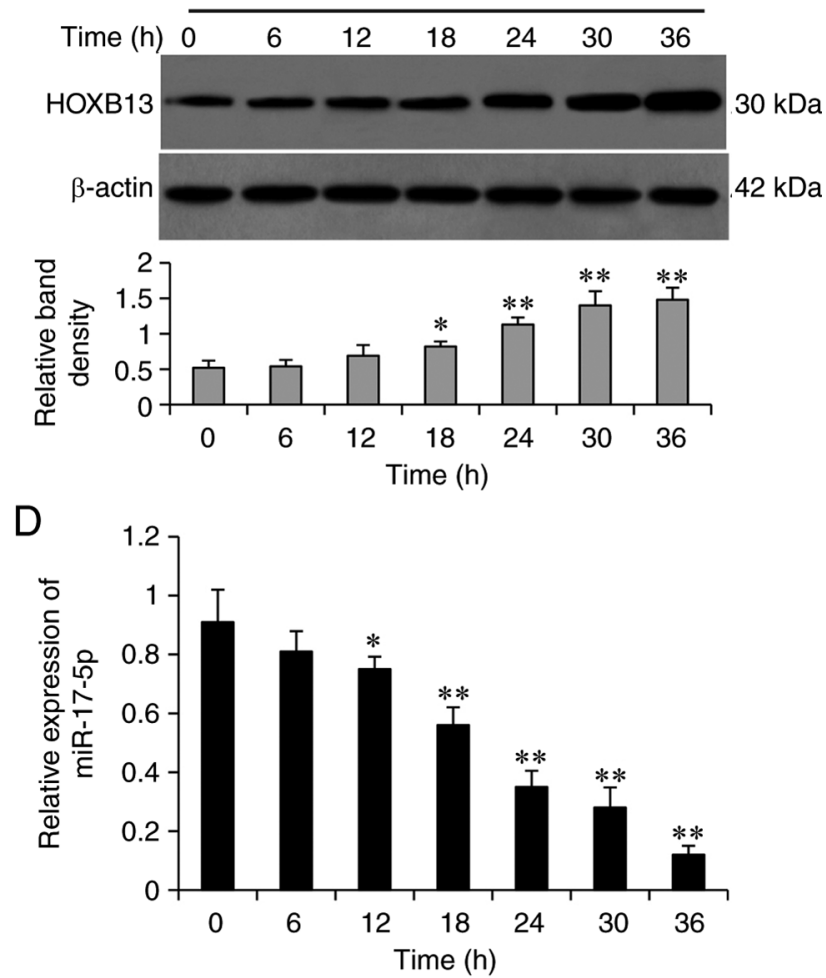

$\mathrm{F}$

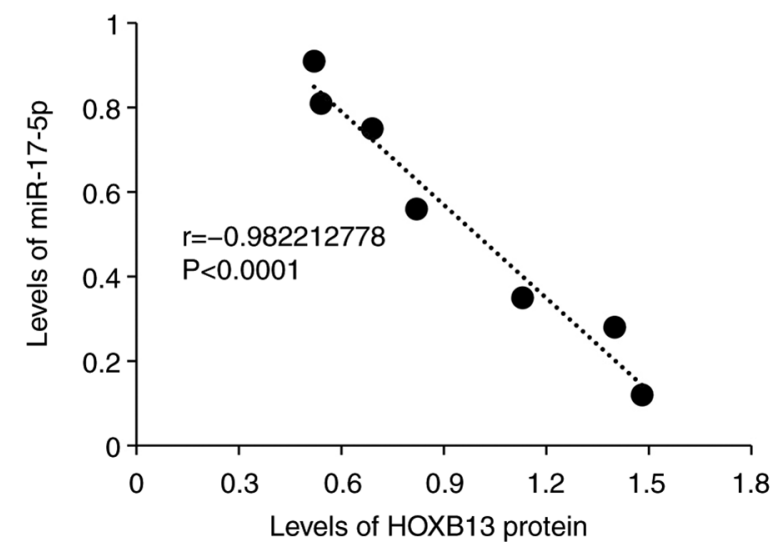

Figure 3. PDGF-BB stimulation increases HOXB13 expression and reduces miR-17-5p expression in VSMCs. Cells were incubated with 15 ng/ml PDGF-BB protein for different periods and harvested. (A) RT-qPCR was used to detect the mRNA expression level of HOXB13. (B) Western blotting was used to detect the protein expression level of HOXB13 and band density was normalized to $\beta$-actin. (C) The binding sites of miR-17-5p and the 3'-untranslated region of HOXB13 are highly conserved across species. (D) RT-qPCR was used to detect the expression level of miR-17-5p. The correlation of the (E) mRNA and (F) protein expression levels of HOXB13 with the expression of miR-17-5p was analyzed using a Pearson's test. The correlation coefficient is denoted as ' $r$ '. ${ }^{*} \mathrm{P}<0.05$ and ${ }^{* *} \mathrm{P}<0.001$ vs. 0 h. PDGF-BB, platelet-derived growth factor-BB; VSMCs, vascular smooth muscle cells; miR, microRNA; HOXB13, homeobox B13; RT-qPCR, reverse transcription-quantitative PCR.

in a time-dependent manner, as determined via RT-qPCR and western blot analyses, respectively (Fig. 3A and B). Using multiple miRNA prediction tools, the potential upstream miRNAs that target HOXB13 were examined. miR-17-5p was found to have a 7-base perfect binding site and a 5-base imperfect binding site with the 3'-UTR of HOXB13 mRNA, and the binding sites were highly conserved across species (Fig. 3C), indicating that miR-17-5p may be a potential miRNA to regulate HOXB13. Moreover, a literature search supported the involvement of miR-17-5p in the phenotypic modulation of VSMCs (12). It was demonstrated that the expression levels of miR-17-5p were significantly decreased in VSMCs upon PDGF-BB stimulation in a time-dependent manner (Fig. 3D).
Furthermore, HOXB13 mRNA (Fig. 3E) and protein (Fig. 3F) expression levels were very strongly negatively correlated with those of miR-17-5p in VSMCs given PDGF-BB stimulation for different durations, as determined using a Pearson's test.

miR-17-5p negatively regulates the expression level of HOXB13 in VSMCs. Based on the identified binding sites, the WT and MT pMIR-REPORT luciferase report vectors were constructed (Fig. 4A). VSMCs were co-transfected with the WT vector and miR-17-5p mimics oligonucleotides, and the luciferase assays revealed that miR-17-5p inhibited luciferase activities in a concentration-dependent manner (Fig. 4B). In addition, the miR-17-5p mimics significantly decreased, 
A

\begin{tabular}{|c|c|c|c|c|}
\hline \multicolumn{4}{|c|}{ pMIR-luc-HOXB13-3'UTR } & \multirow[b]{2}{*}{ Poly A } \\
\hline SV40 & \multicolumn{2}{|l|}{ Luciferase } & HOXB13 3'-UTR & \\
\hline \multicolumn{5}{|c|}{ (WT) } \\
\hline \multicolumn{2}{|c|}{$\begin{array}{l}\text { Rat HOXB13 3'-UTR: } \\
\text { (Perfect binding sites) }\end{array}$} & \multicolumn{3}{|c|}{$\begin{array}{l}\text { 5'-CUAGAGCUCUGUAGAGCACUUUA-3' } \\
\qquad|||||||||| \mid\end{array}$} \\
\hline \multicolumn{2}{|r|}{ rno-miR-17-5p: 3} & \multicolumn{3}{|c|}{ 3'-AUGGACGUGACAUU--CGUGAAAC-5' } \\
\hline \multicolumn{2}{|c|}{ Rat HOXB13 3'-UTR: } & $5^{\prime}-\mathrm{C}$ & GCUGCACUGAAU & AACA-3 \\
\hline
\end{tabular}

C

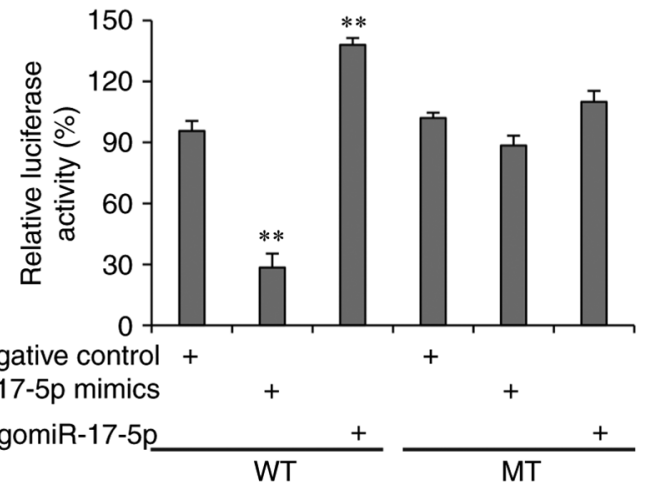

D

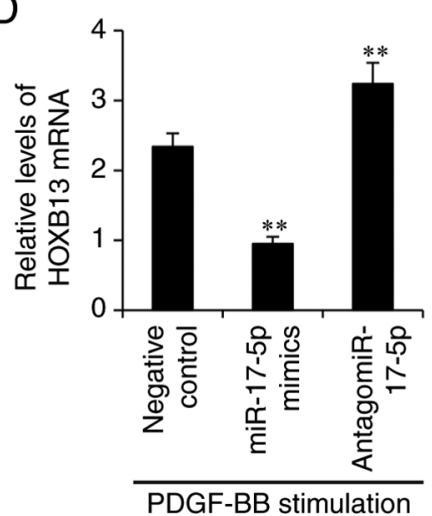

$\mathrm{B}$

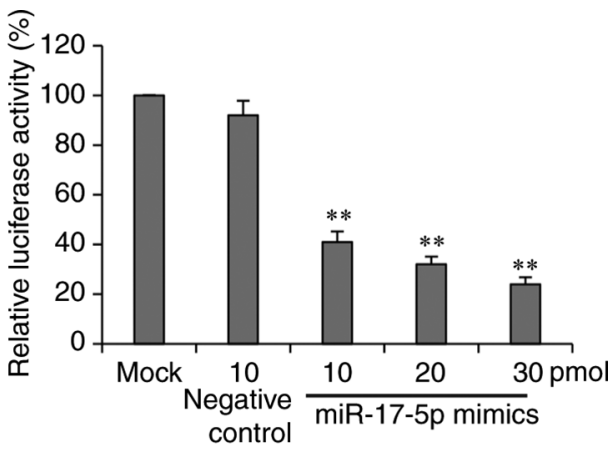

E

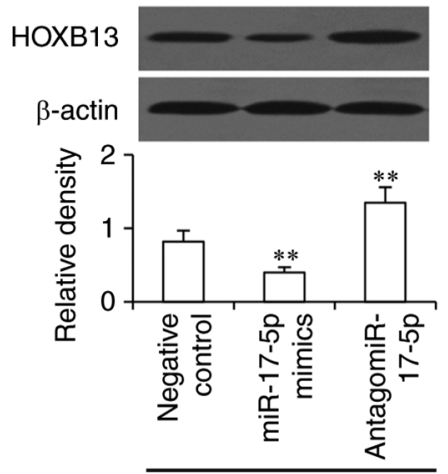

PDGF-BB stimulation

Figure 4. miR-17-5p negatively regulates the expression of HOXB13 by specifically binding to its 3'-UTR in VSMCs. (A) The WT and MT pMIR-REPORT luciferase report vectors were constructed. (B) VSMCs were either mock-treated or co-transfected with the WT luciferase vector and 10 pmol negative control or miR-17-5p mimics oligonucleotides at different concentrations. (C) VSMCs were co-transfected with WT or MT luciferase reporter vectors, and negative control, miR-17-5p mimics or antagomiR-17-5p oligonucleotides. Luciferase activities are shown in (B) and (C) VSMCs were transfected with negative control, miR-17-5p mimics or antagomiR-17-5p oligonucleotides, and then subjected to reverse transcription-quantitative PCR and western blot analyses for detecting the (D) mRNA and (E) protein expression levels of HOXB13, respectively. Band density was normalized to $\beta$-actin in (E) ${ }^{* *} \mathrm{P}<0.001$ vs. negative control-transfected cells. WT, wild-type; MT, mutated type; PDGF-BB, platelet-derived growth factor-BB; VSMCs, vascular smooth muscle cells; miR, microRNA; HOXB13, homeobox B13; UTR, untranslated region.

while antagomiR-17-5p significantly increased, the luciferase activity in cells co-transfected with the WT vector but not the MT vector (Fig. 4C). Moreover, the miR-17-5p mimics significantly reduced, while the antagomiR-17-5p significantly increased, the mRNA (Fig. 4D) and protein (Fig. 4E) expression levels of HOXB13. These results indicated that miR-17-5p served a negative regulatory role on HOXB13 expression by binding to its 3'-UTR in VSMCs.

miR-17-5p inhibits the proliferation and phenotypic switching of VSMCs. Transfection of mimic negative control had no effect on, while miR-17-5p transfection significantly increased, the expression level of miR-17-5p in VSMCs (Fig. 5A). Transfection of antagomiR negative control had no effect on, while antagomiR-17-5p transfection significantly decreased, the expression level of miR-17-5p in VSMCs (Fig. 5B). Because neither mimic nor antagomiR negative controls affected miR-17-5p expression level, mimic negative control was used as a negative control in the subsequent experiments. Transfection of miR-17-5p mimics significantly inhibited the proliferation of VSMCs under PDGF-BB stimulation, while the antagomiR-17-5p significantly promoted the proliferation of VSMCs without PDGF-BB stimulation (Fig. 5C). Furthermore, miR-17-5p mimics transfection downregulated the expression levels of HOXB13 and PCNA, and increased the expression levels of $\alpha$-SMA, transgelin and smoothelin in VSMCs under PDGF-BB stimulation. However,
antagomiR-17-5p transfection showed the opposite effects in VSMCs without PDGF-BB stimulation (Fig. 5D).

Knockdown of HOXB13 using siRNA inhibits the proliferation and phenotype switching of VSMCs. Knockdown of HOXB13 using siRNA significantly inhibited the proliferation of VSMCs in the presence or absence of PDGF-BB stimulation, compared with the negative controls (Fig. 6A). siRNA HOXB13 also significantly decreased the mRNA (Fig. 6B) and protein (Fig. 6C) expression levels of HOXB13 in VSMCs in the presence or absence of PDGF-BB stimulation. In addition, transfection of siRNA HOXB13 significantly decreased the expression level of PCNA and increased that of $\alpha$-SMA, compared with the negative control (Fig. 6C).

VSMC proliferation, migration and phenotype switching are regulated via the miR-17-5p/HOXB13 axis. Compared with the negative control, the antagomiR-17-5p significantly promoted the proliferation of VSMCs, while knockdown of HOXB13 using siRNA abolished this effect (Fig. 7A). The antagomiR-17-5p also increased the migratory capability of VSMCs but knockdown of HOXB13 abrogated this effect (Fig. 7B and C). Moreover, the antagomiR-17-5p significantly increased the expression levels of HOXB13, PCNA, MMP-2 and MMP-9, and downregulated $\alpha$-SMA expression, while HOXB13 knockdown could reverse these effects (Fig. 7D). 
A

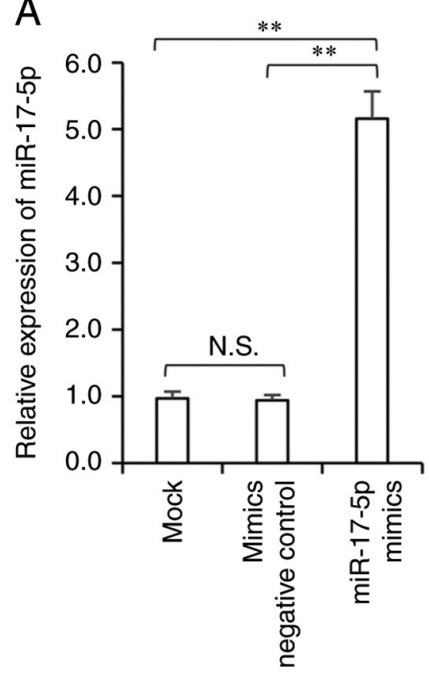

D

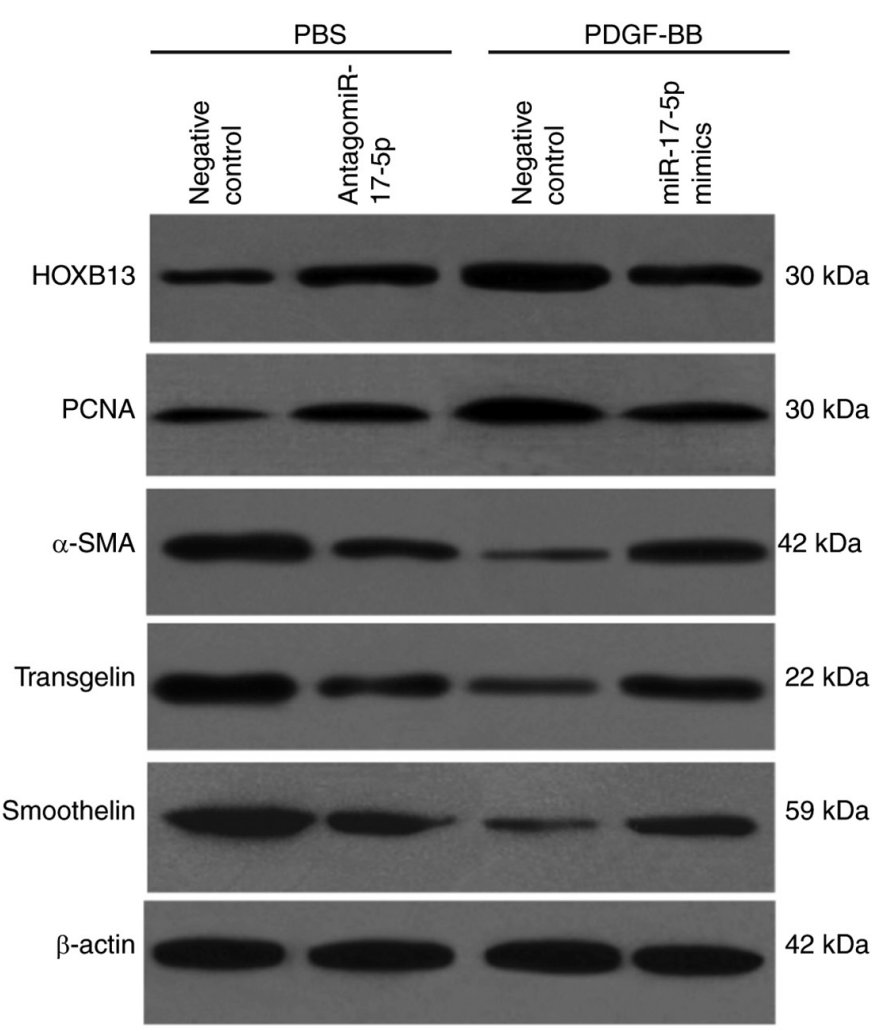

$\mathrm{B}$

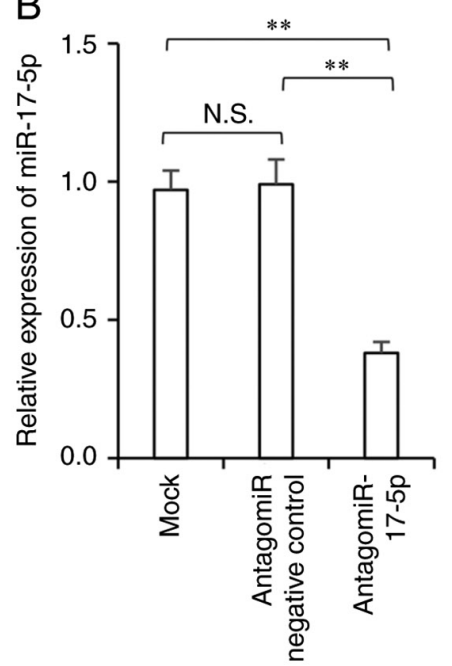

C
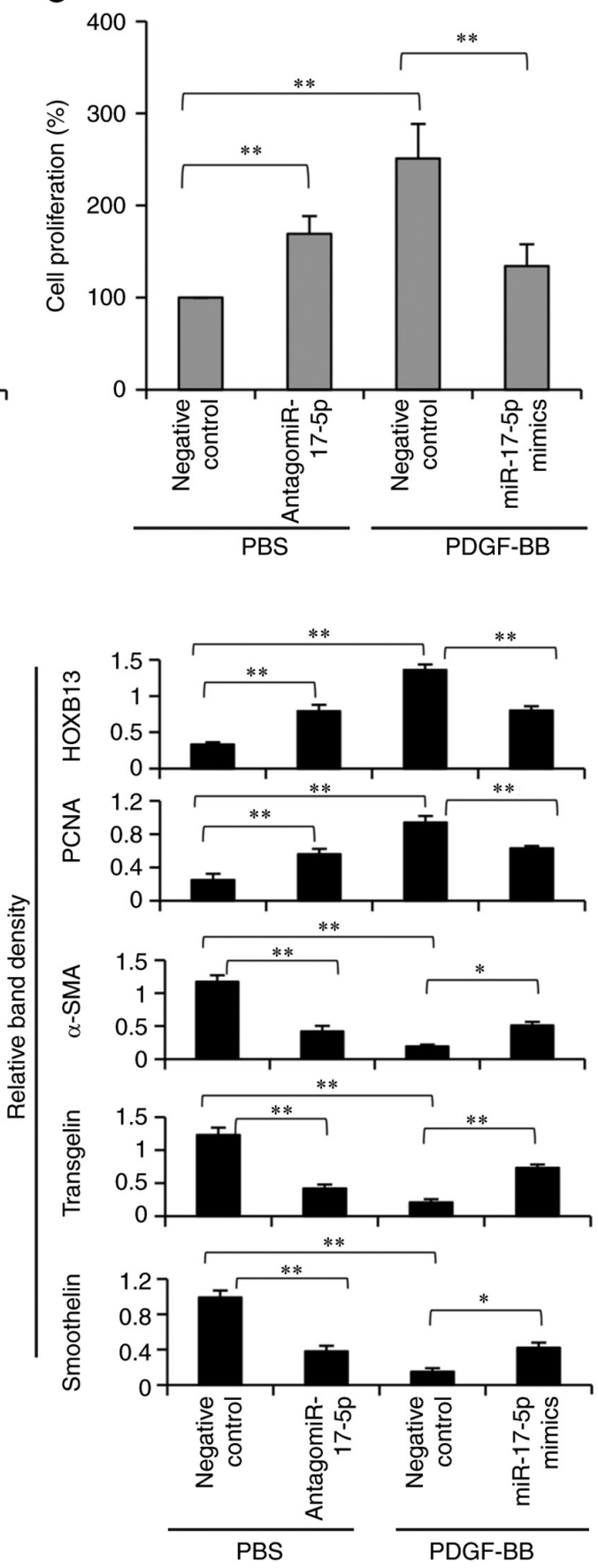

Figure 5. miR-17-5p regulates the proliferation and phenotypic switching of VSMCs. (A) VSMCs were mock-treated, or transfected with mimics negative control or miR-17-5p mimics oligonucleotides, and the expression level of miR-17-5p was detected via RT-qPCR. (B) VSMCs were mock-treated, or transfected with antagomiR negative control or antagomiR-17-5p oligonucleotides, and the expression level of miR-17-5p was detected RT-qPCR. VSMCs transfected with negative control, miR-17-5p mimics or antagomiR-17-5p oligonucleotides were incubated in the absence or presence of PDGF-BB protein for $24 \mathrm{~h}$. (C) Cell proliferation was measured. (D) Cells were subjected to western blot analysis and band density was normalized to $\beta$-actin. ${ }^{*} \mathrm{P}<0.05$ and ${ }^{* *} \mathrm{P}<0.001$. N.S., not significant; PDGF-BB, platelet-derived growth factor-BB; VSMCs, vascular smooth muscle cells; miR, microRNA; RT-qPCR, reverse transcription-quantitative PCR; PCNA, proliferating cell nuclear antigen; $\alpha$-SMA, $\alpha$-smooth muscle actin.

\section{Discussion}

Previous studies have reported that the transformation of VSMCs from a highly differentiated phenotype to a poorly differentiated phenotype leads to egregious cell proliferation, migration and excessive synthesis of extracellular matrix, resulting in a series of pathological changes, such as vascular intimal hyperplasia or even luminal stenosis $(1,2,12,20-22)$.
Unfortunately, there are a lack of effective treatment strategies for this disorder. Therefore, it is crucial to elucidate the molecular mechanisms underlying the phenotypic switch, proliferation and migration of VSMCs. A culture of primary VSMCs under PDGF-BB stimulation is the most commonly used in vitro model to study this specific pathophysiological response (23). By adopting this model, the current study identified a novel miR-17-5p/HOXB13 axis that participates 
A

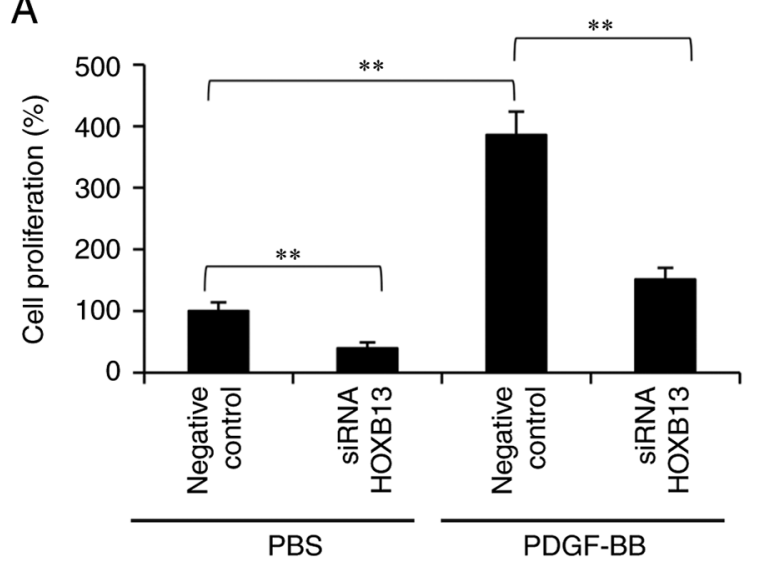

B

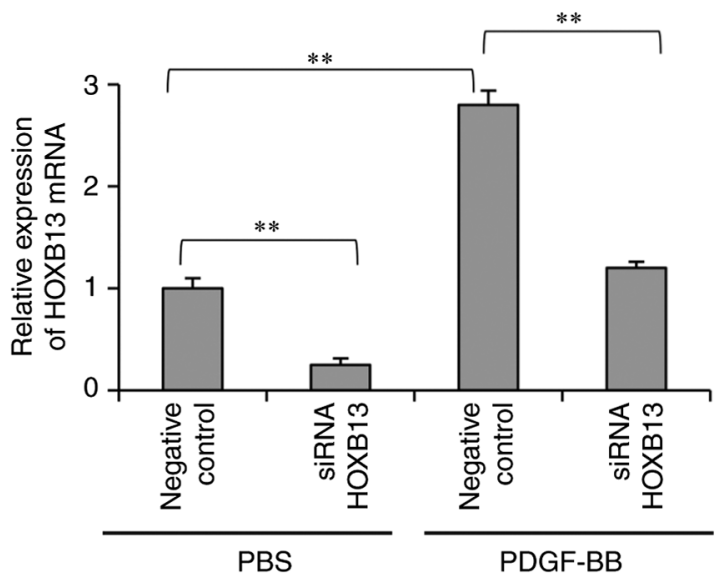

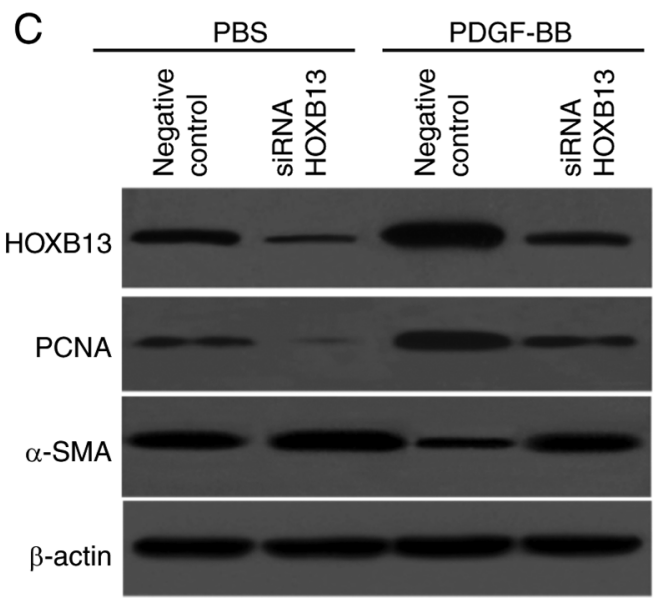

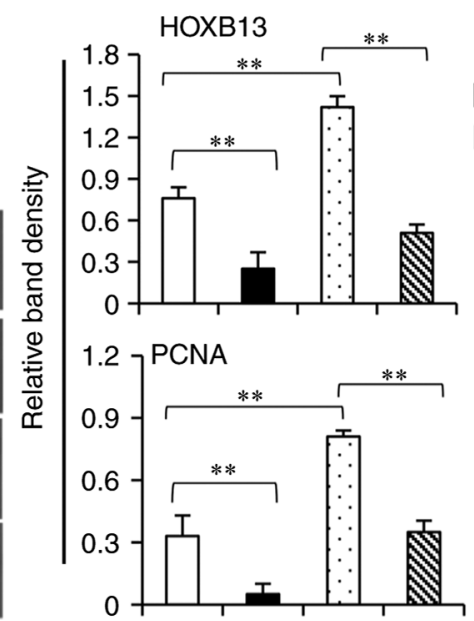

$\left.\begin{array}{l}\text { Negative control } \\ \text { siRNA HOXB13 }\end{array}\right\}$ PBS
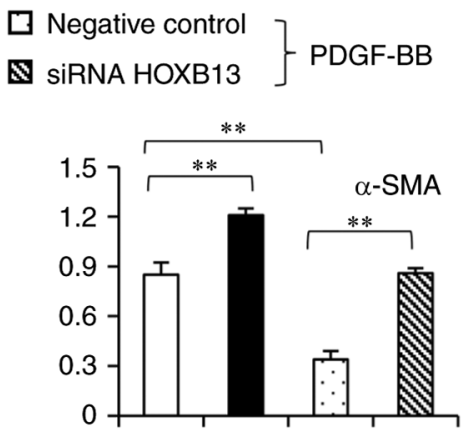

Figure 6. Knockdown of HOXB13 inhibits the proliferation of VSMCs. VSMCs were transfected with negative control or siRNA HOXB13 oligonucleotides and incubated in the absence or presence of PDGF-BB protein for $24 \mathrm{~h}$. (A) Cell proliferation was measured. (B) The mRNA expression level of HOXB13 was detected via reverse transcription-quantitative PCR. (C) Cells were subjected to western blot analysis and band density was normalized to $\beta$-actin. ${ }^{* *} \mathrm{P}<0.001$. PDGF-BB, platelet-derived growth factor-BB; VSMCs, vascular smooth muscle cells; siRNA, small interfering RNA; HOXB13, homeobox B13; PCNA, proliferating cell nuclear antigen; $\alpha$-SMA, $\alpha$-smooth muscle actin.

in the regulation of the phenotypic transformation of VSMCs. However, this axis has not been validated in in vivo models, which is a limitation of the present study.

miRNAs serve a key role in the regulation of cell differentiation, proliferation and migration by inhibiting the translation of target genes or promoting the degradation of mRNAs (3). Previous in vivo and in vitro studies have revealed that miRNAs were key molecular regulators involved in the process of vascular intimal hyperplasia. For instance, miR-663 regulated the phenotypic switching of VSMCs by targeting JunB and myosin light chain 9 (24), while miR-15b and miR-16 promoted the conversion of VSMCs to a contractile phenotype and inhibited vascular neointima formation by targeting Yes-associated protein (21). Moreover, miR-22 suppressed the formation of vascular neointima by downregulating methyl-CpG binding protein 2 , histone deacetylase 4 and ecotropic virus integration site 1 protein homolog, and upregulating the expression levels of VSMC marker genes including $\alpha$-SMA and smooth muscle myosin heavy chain (22). It has also been shown that miR-145 overexpression inhibited intimal hyperplasia by increasing the expression level of myosin heavy chain smooth muscle- 2 and reducing the expression level of the proliferation marker Ki-67 in a rabbit model of vein graft disease (25). Furthermore, miR-143 and miR-145 cooperatively promote the differentiation and repress the proliferation of VSMCs by targeting multiple genes (26), and the reduced expression of miR-143 and miR-145 by cholesterol loading decreases the differentiation of VSMCs (27). These studies indicate that numerous miRNAs contribute to intimal hyperplasia by modulating the phenotypic transformation, proliferation and migration of VSMCs.

In a recent study, Li et al (12) reported that miR-17 knockdown promoted the phenotypic switching of VSMCs via the upregulation of interferon regulatory factor 9, which was in agreement with the present results, although miR-17 was shown to target different genes between the two studies. Interestingly, a study by Yang et al (28) revealed that miR-17 promoted the proliferation of VSMCs when upregulated by

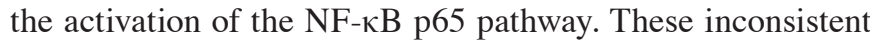
results indicate that the role of miR-17 may be cell-specific, as the study by Yang et al (28) used human VSMCs, while primary mouse and rat VSMCs were utilized in the study by Li et al (12) and the present study. Moreover, miR-26a has been shown to promote the proliferation and inhibit the differentiation of human VSMCs by altering the TGF- $\beta$ pathway signaling (29), but exerted an opposite effect on rat jugular vein VSMCs by targeting mitogen-activated protein kinase 6 (30). The miR-17-92 cluster (consisting of six mature 
A

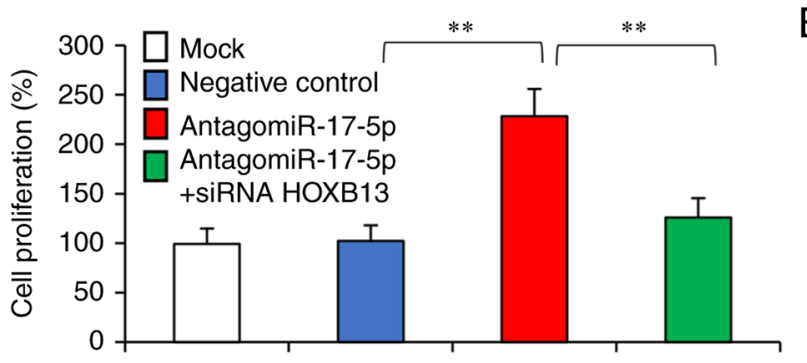

C
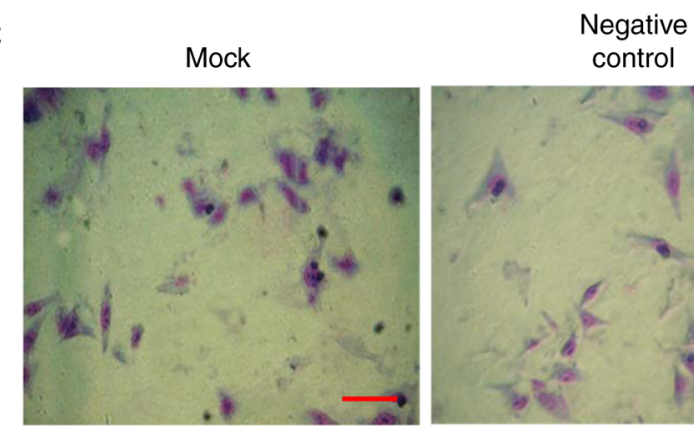

control

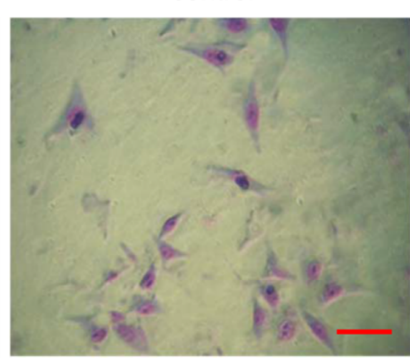

B
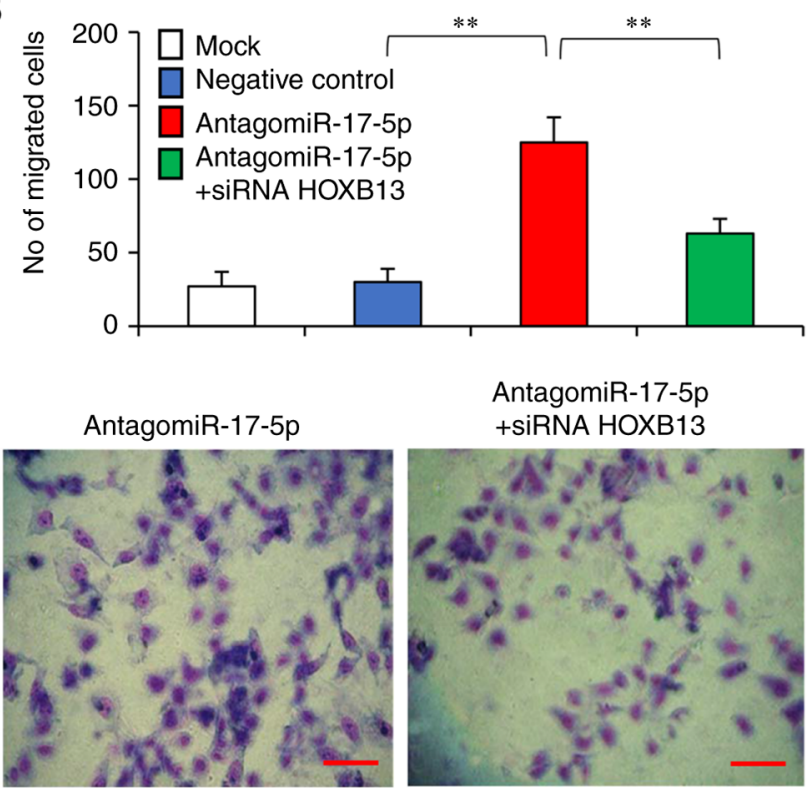

D

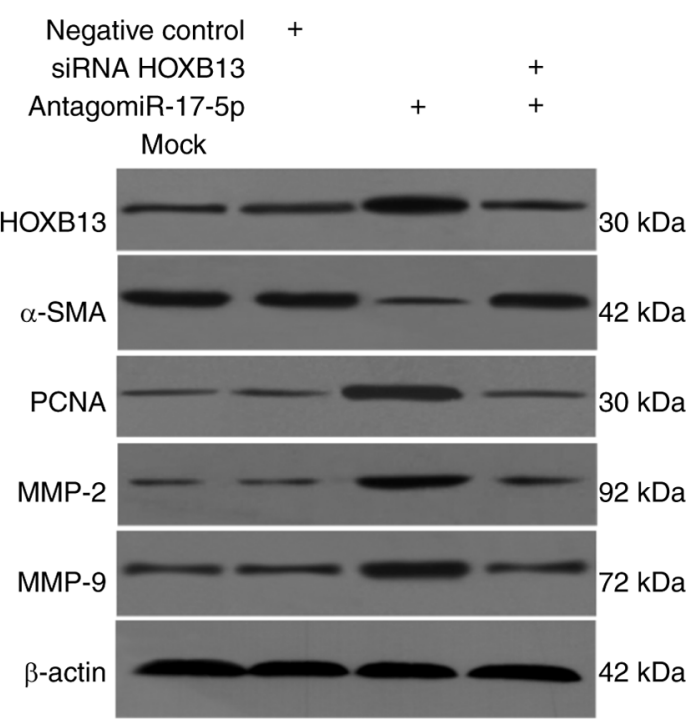

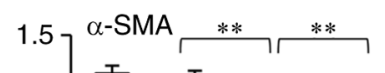
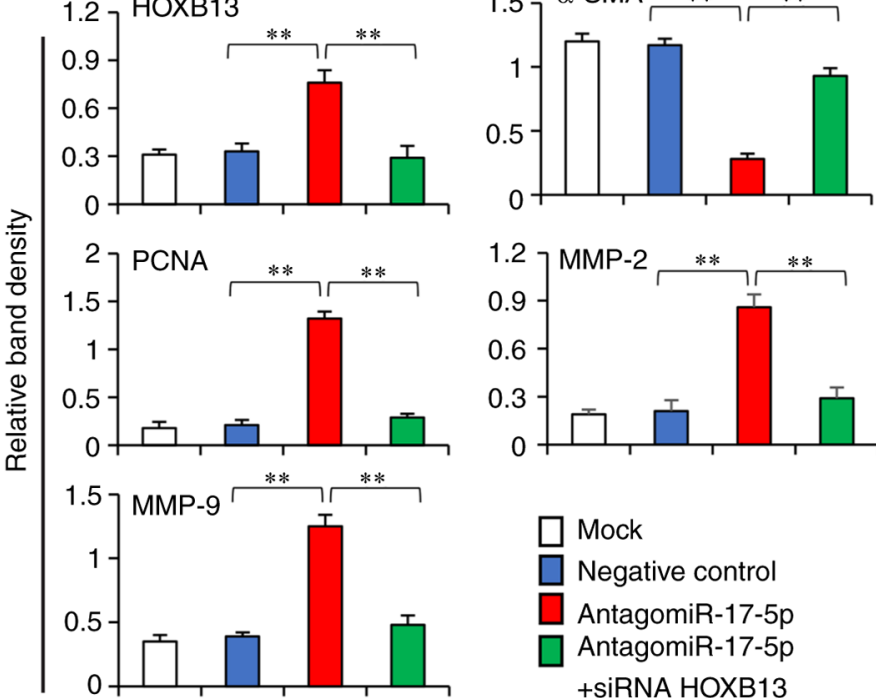

Figure 7. VSMC proliferation and migration are regulated via the miR-17-5p/HOXB13 axis. VSMCs were transfected with negative control, antagomiR-17-5p or antagomiR-17-5p + siRNA HOXB13 oligonucleotides and incubated for $24 \mathrm{~h}$. (A) Cell proliferation was measured. Cells were subjected to Transwell migration assay and (B) the number of migrated cells was counted. (C) Migrated cells were stained with crystal violet solution. Scale bar, $100 \mu \mathrm{m}$. (D) Cells were subjected to western blot analysis and band density was normalized to $\beta$-actin. Mock-treated cells served as controls. ${ }^{* *} \mathrm{P}<0.001$ vs. negative control-treated cells. PDGF-BB, platelet-derived growth factor-BB; VSMCs, vascular smooth muscle cells; siRNA, small interfering RNA; HOXB13, homeobox B13; miR, microRNA; PCNA, proliferating cell nuclear antigen; $\alpha$-SMA, $\alpha$-smooth muscle actin.

miRNAs including miR-17, miR-18a, miR-19a, miR-19b, miR-20a and miR-92a) increased the proliferation of mouse VSMCs when its maturation was facilitated by DiGeorge critical region 8 (31), and promoted the proliferation of human pulmonary artery VSMCs by inhibiting prolyl hydroxylase 2 and inducing hypoxia-inducible factors (32). Based on the presence of the regulatory mechanisms between miRNAs (3), the results of the two previous studies $(31,32)$ do not suggest that miR-17 alone has the same function as the miR-17-92 cluster in enhancing the proliferation of VSMCs. The miRNA regulatory network is extremely complex; one miRNA can regulate multiple target genes, while one target gene may be regulated by multiple miRNAs, and the regulatory function of miRNAs is affected by several factors (3). Therefore, the function of miR-17-5p in the phenotypic switching, proliferation and migration of VSMCs requires further investigation.

As a homeobox transcription factor, HOXB13 serves an important role in regulating the proliferation, differentiation and invasion of cells from various cancer types (33). HOXB13 has been considered to be a prognostic indicator for prostate cancer as it is found to be mutated in families with an increased risk of early-onset hereditary prostate cancer (34). The function of HOXB13 in a variety of diseases has been reported in recent years (8). It has been shown that HOXB13 contributes to the maturation and proliferation of infant cardiomyocytes (35). Moreover, HOXB13 is highly expressed in liver fibrotic tissues and its expression level is positively correlated with the degree of liver inflammation and fibrosis (36). To the best of our 
knowledge, the present study may be the first to reveal the role of HOXB13 in regulating the proliferation, migration and phenotypic switch of VSMCs.

In conclusion, the present study demonstrated that HOXB13 was upregulated, while miR-17-5p was downregulated in VSMCs upon PDGF-BB stimulation. Furthermore, the current study revealed the regulatory link between miR-17-5p and HOXB13, and elucidated some of the mechanisms accounting for the phenotypic modulation and the changes in the biological behaviors of VSMCs. It was found that miR-17-5p specifically binds to the 3'-UTR of HOXB13 to downregulate its expression. The miR-17-5p/HOXB13 axis was shown to be involved in the phenotypic switching, proliferation and migration of VSMCs by regulating the expression of the VSMC markers $\alpha$-SMA, transgelin and smoothelin, the cell proliferating marker PCNA and the cell migration proteins MMP-2 and MMP-9. Collectively, the present results indicated that these factors may represent potential therapeutic targets for the management of intimal hyperplasia.

\section{Acknowledgements}

Not applicable.

\section{Funding}

This study was supported by General grants of Medical Science and Technology Development in Nanjing City, China (grant no. YKK18211).

\section{Availability of data and materials}

The datasets used and/or analyzed during the current study are available from the corresponding author on reasonable request.

\section{Authors' contributions}

$\mathrm{HZ}$ conceived and designed the study, and finalized the manuscript. TY and TW performed the experiments. SK and GZ contributed to data collection and analysis. KZ contributed to the result interpretation and manuscript revision. TY and TW drafted the manuscript. All authors read and approved the final manuscript. TY and HZ confirming the authenticity of all the raw data. TY and TW contributed equally to this work.

\section{Ethics approval and consent to participate}

The study had been approved by the Animal Ethics Committee of Nanjing Jiangning Hospital, (Nanjing, China; approval no. IACUC-2004055). It is confirmed that animals were anesthetized and sacrificed using acceptable methods.

\section{Patient consent for publication}

Not applicable.

\section{Competing interests}

The authors declare that they have no competing interests.

\section{References}

1. Wang G, Jacquet L, Karamariti E and Xu Q: Origin and differentiation of vascular smooth muscle cells. J Physiol 593: 3013-3030, 2015.

2. Alexander MR and Owens GK: Epigenetic control of smooth muscle cell differentiation and phenotypic switching in vascular development and disease. Annu Rev Physiol 74: 13-40, 2012.

3. Bartel DP: MicroRNAs: Genomics, biogenesis, mechanism, and function. Cell 116: 281-297, 2004.

4. Ha M and Kim VN: Regulation of microRNA biogenesis. Nat Rev Mol Cell Biol 15: 509-524, 2014.

5. Mellis D and Caporali A: MicroRNA regulation of vascular function. Vasc Biol 1: H41-H46, 2019.

6. Wang D and Atanasov AG: The microRNAs regulating vascular smooth muscle cell proliferation: A minireview. Int J Mol Sci 20: 324, 2019.

7. Holland PW: Evolution of homeobox genes. Wiley Interdiscip Rev Dev Biol 2: 31-45, 2013.

8. Aspuria PJ, Cheon DJ, Gozo MC, Beach JA, Recouvreux MS, Walts AE, Karlan BY and Orsulic S: HOXB13 controls cell state through super-enhancers. Exp Cell Res 393: 112039, 2020.

9. Cantile M, Schiavo G, Terracciano L and Cillo C: Homeobox genes in normal and abnormal vasculogenesis. Nutr Metab Cardiovasc Dis 18: 651-658, 2008.

10. Attard G,Parker C, Eeles RA, Schröder F, Tomlins SA, Tannock I, Drake CG and de Bono JS: Prostate cancer. Lancet 387: 70-82, 2016.

11. Livak KJ and Schmittgen TD: Analysis of relative gene expression data using real-time quantitative PCR and the 2(-Delta Delta C(T)) method. Methods 25: 402-408, 2001.

12. Li W, Deng P, Wang J, Li Z and Zhang H: MiR-17 knockdown promotes vascular smooth muscle cell phenotypic modulation through upregulated interferon regulator Factor 9 expression. Am J Hypertens 33: 1119-1126, 2020.

13. Lee MH, Kwon BJ, Koo MA, You KE and Park JC: Mitogenesis of vascular smooth muscle cell stimulated by platelet-derived growth factor-bb is inhibited by blocking of intracellular signaling by epigallocatechin-3-O-gallate. Oxid Med Cell Longev 2013: 827905, 2013.

14. Risinger GM Jr, Hunt TS, Updike DL, Bullen EC and Howard EW: Matrix metalloproteinase- 2 expression by vascular smooth muscle cells is mediated by both stimulatory and inhibitory signals in response to growth factors. J Biol Chem 281: 25915-25925, 2006.

15. Hsuan CF, Lu YC, Tsai IT, Houng JY, Wang SW, Chang TH, Chen YL and Chang CC: Glossogyne tenuifolia attenuates proliferation and migration of vascular smooth muscle cells. Molecules 25: 5832, 2020.

16. Xin $\mathrm{H}$, Wang $\mathrm{Z}$, Wu S, Wang $\mathrm{P}$, Tao $\mathrm{X}, \mathrm{Xu} \mathrm{C}$ and You L: Calcified decellularized arterial scaffolds impact vascular smooth muscle cell transformation via downregulating $\alpha$-SMA expression and upregulating OPN expression. Exp Ther Med 18: 705-710, 2019.

17. Je HD and Sohn UD: SM22alpha is required for agonist-induced regulation of contractility: Evidence from SM22alpha knockout mice. Mol Cells 23: 175-181, 2007.

18. van Eys GJ, Niessen PM and Rensen SS: Smoothelin in vascular smooth muscle cells. Trends Cardiovasc Med 17: 26-30, 2007.

19. Newby AC: Matrix metalloproteinases regulate migration, proliferation, and death of vascular smooth muscle cells by degrading matrix and non-matrix substrates. Cardiovasc Res 69: 614-624, 2006.

20. Dzau VJ, Braun-Dullaeus RC and Sedding DG: Vascular proliferation and atherosclerosis: New perspectives and therapeutic strategies. Nat Med 8: 1249-1256, 2002.

21. Xu F, Ahmed AS, Kang X, Hu G, Liu F, Zhang W and Zhou J: MicroRNA-15b/16 attenuates vascular neointima formation by promoting the contractile phenotype of vascular smooth muscle through targeting YAP. Arterioscler Thromb Vasc Biol 35: 2145-2152, 2015.

22. Yang F, Chen Q, He S, Yang M, Maguire EM, An W, Afzal TA, Luong LA, Zhang L and Xiao Q: miR-22 Is a novel mediator of vascular smooth muscle cell phenotypic modulation and neointima formation. Circulation 137: 1824-1841, 2018.

23. Montezano AC, Lopes RA, Neves KB, Rios F and Touyz RM: Isolation and culture of vascular smooth muscle cells from small and large vessels. Methods Mol Biol 1527: 349-354, 2017. 
24. Li P, Zhu N, Yi B, Wang N, Chen M, You X, Zhao X, Solomides CC, Qin Y and Sun J: MicroRNA-663 regulates human vascular smooth muscle cell phenotypic switch and vascular neointimal formation. Circ Res 113: 1117-1127, 2013.

25. Ohnaka M, Marui A, Yamahara K, Minakata K, Yamazaki K, Kumagai M, Masumoto H, Tanaka S, Ikeda T and Sakata R: Effect of microRNA-145 to prevent vein graft disease in rabbits by regulation of smooth muscle cell phenotype. J Thorac Cardiovasc Surg 148: 676-682.e2, 2014.

26. Cordes KR, Sheehy NT, White MP, Berry EC, Morton SU, Muth AN, Lee TH, Miano JM, Ivey KN and Srivastava D: miR-145 and miR-143 regulate smooth muscle cell fate and plasticity. Nature 460: 705-710, 2009.

27. Vengrenyuk Y, Nishi H,Long X, Ouimet M, Savji N, Martinez FO, Cassella CP, Moore KJ, Ramsey SA, Miano JM and Fisher EA: Cholesterol loading reprograms the microRNA-143/145-myocardin axis to convert aortic smooth muscle cells to a dysfunctional macrophage-like phenotype. Arterioscler Thromb Vasc Biol 35: 535-546, 2015.

28. Yang D, Sun C, Zhang J, Lin S, Zhao L, Wang L, Lin R, Lv J and Xin S: Proliferation of vascular smooth muscle cells under inflammation is regulated by NF- $\kappa \mathrm{B}$ p65/microRNA-17/RB pathway activation. Int J Mol Med 41: 43-50, 2018.

29. Leeper NJ, Raiesdana A, Kojima Y, Chun HJ, Azuma J, Maegdefessel L, Kundu RK, Quertermous T, Tsao PS and Spin JM: MicroRNA-26a is a novel regulator of vascular smooth muscle cell function. J Cell Physiol 226: 1035-1043, 2011.

30. Tan J, Yang L, Liu C and Yan Z: MicroRNA-26a targets MAPK6 to inhibit smooth muscle cell proliferation and vein graft neointimal hyperplasia. Sci Rep 7: 46602, 2017.
31. Chen Z, Wu J, Yang C, Fan P, Balazs L, Jiao Y, Lu M, Gu W, Li C, Pfeffer LM, et al: DiGeorge syndrome critical region 8 (DGCR8) protein-mediated microRNA biogenesis is essential for vascular smooth muscle cell development in mice. J Biol Chem 287: 19018-19028, 2012.

32. Chen T, Zhou Q, Tang H, Bozkanat M, Yuan JX, Raj JU and Zhou G: miR-17/20 Controls prolyl hydroxylase 2 (PHD2)/ Hypoxia-Inducible Factor 1 (HIF1) to regulate pulmonary artery smooth muscle cell proliferation. J Am Heart Assoc 5: e004510, 2016.

33. Wang X, Sun Y, Xu T, Qian K, Huang B, Zhang K, Song Z, Qian T, Shi J and Li L: HOXB13 promotes proliferation, migration, and invasion of glioblastoma through transcriptional upregulation of lncRNA HOXC-AS3. J Cell Biochem 120: 15527-15537, 2019.

34. Ewing CM, Ray AM, Lange EM, Zuhlke KA, Robbins CM, Tembe WD, Wiley KE, Isaacs SD, Johng D, Wang Y, et al: Germline mutations in HOXB13 and prostate-cancer risk. N Engl J Med 366: 141-149, 2012.

35. Nguyen NUN, Canseco DC, Xiao F, Nakada Y, Li S, Lam NT, Muralidhar SA, Savla JJ, Hill JA, Le V, et al: A calcineurin-Hoxb13 axis regulates growth mode of mammalian cardiomyocytes. Nature 582: 271-276, 2020.

36. Zuo L, Tan T, Wei C, Wang H, Tan L, Hao Y, Qian J, Chen Y and Wu C: HOXB13 expression is correlated with hepatic inflammatory activity of patients with hepatic fibrosis. J Mol Histol 51: 183-189, 2020.

(i) (9) This work is licensed under a Creative Commons Attribution-NonCommercial-NoDerivatives 4.0 International (CC BY-NC-ND 4.0) License. 